\title{
Alain Niderst, La poésie à l'âge baroque (1598-1660)
}

\section{Monica Pavesio}

\section{(2) OpenEdition}

\section{Journals}

\section{Edizione digitale}

URL: http://journals.openedition.org/studifrancesi/30162

DOI: 10.4000/studifrancesi.30162

ISSN: 2427-5856

\section{Editore}

Rosenberg \& Sellier

\section{Edizione cartacea}

Data di pubblicazione: 1 avril 2006

Paginazione: 147

ISSN: 0039-2944

\section{Notizia bibliografica digitale}

Monica Pavesio, «Alain Niderst, La poésie à l'âge baroque (1598-1660)», Studi Francesi [Online], 148 (XLX | I) | 2006, online dal 30 novembre 2015, consultato il 24 avril 2021. URL: http://

journals.openedition.org/studifrancesi/30162 ; DOI: https://doi.org/10.4000/studifrancesi.30162

\section{Questo documento è stato generato automaticamente il 24 avril 2021.}

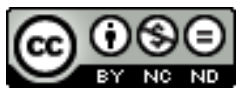

Studi Francesi è distribuita con Licenza Creative Commons Attribuzione - Non commerciale - Non opere derivate 4.0 Internazionale. 


\title{
Alain Niderst, La poésie à l'âge baroque (1598-1660)
}

\author{
Monica Pavesio
}

\section{NOTIZIA}

ALAIN NIDERST, La poésie à l'âge baroque (1598-1660), Paris, Robert Laffont, 2005, pp. 877.

1 L'antologia curata da Alain Niderst raccoglie le opere poetiche di un centinaio di autori della prima metà del XVII secolo, appartenenti all'età barocca, un periodo a lungo sottovalutato, ed oggi pienamente riabilitato, che contrariamente al classicismo privilegia l'esuberanza e l'asimmetria.

2 Come spiega il curatore nell'interessante introduzione, nessuna epoca della letteratura francese è stata così ricca di poeti come il periodo che va dall'inizio del regno di Enrico IV alla fine di quello di Luigi XIII. I romantici, d'altra parte, non si sono sbagliati nell'affermare che nel periodo barocco, il poeta inizia per la prima volta ad utilizzare il pronome personale soggetto di prima persona singolare "je".

Dopo alcune pagine dedicate alla nozione di "barocco" e a quelle correlate di "précieux", "galant" e "coquet", Niderst inserisce una dettagliata ed utile cronologia degli eventi politici, sociali, intellettuali, letterari ed artistici che caratterizzano il periodo preso in esame.

4 Le poesie che compongono la ricca antologia di oltre ottocento pagine sono presentate in ordine cronologico, per permettere al lettore di constatare la straordinaria varietà delle tematiche presenti, che vanno da quelle religiose a quelle amorose e politiche. L'ortografia dei poemi è stata modernizzata, con qualche eccezione dovuta alla necessità del mantenimento delle rime e degli iati.

5 Il curatore ha suddiviso il ricco materiale poetico in tre sezioni, corrispondenti a tre periodi storici. La prima, che va dal 1598 al 1614, denominata "Le roi et les deux reines", si riferisce al regno di Enrico IV ed alle sue due mogli Margherita di Valois, più conosciuta come la regina Margot, e Caterina de Medici; la seconda "Du desordre à la 
dictature" comprende i poemi scritti nel tumultuoso periodo compreso fra il 1614 ed il 1630 , che vede il difficile inizio del regno di Luigi XIII ed il primo periodo del ministero Richelieu; la terza "L'Héroïsme et les mondanités" (1630-1646) riunisce le poesie nazionalistiche e di circostanza volute dal Cardinale per riabilitare il regno, nonché numerosi poemi religiosi, caratteristici di un periodo di guerre e contrasti; l'ultima "De la guerre civile à l'absolutisme" (1646-1660) contiene le opere poetiche scritte durante il periodo della Fronda e di Mazarino.

Il volume si conclude con una breve biografia dei poeti ed una bibliografia essenziale delle loro opere. Alcuni sono autori oggi poco conosciuti, altri sono personaggi molto noti come Pierre Corneille, Cyrano de Bergerac, Paul Scarron, Madeleine de Scudéry, Honoré d'Urfé, che si sono cimentati solo occasionalmente nell'arte della poesia.

7 Una bibliografia generale comprendente le raccolte collettive e le antologie dedicate al XVII secolo, oltre agli studi critici sul barocco e sulla poesia francese del primo Seicento, ed un indice dei poeti citati arricchiscono il volume. 